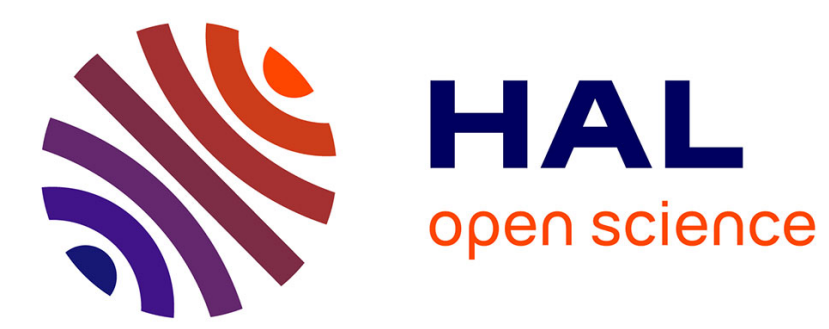

\title{
On the Deposition Kinetics of the LPCVD Gate Oxides Prepared from $\mathrm{SiH} 4$ and $\mathrm{O} 2$
}

\author{
J. Rem, J. Klootwijk, C. Cobianu, J. Holleman, J. Verweij
}

\section{To cite this version:}

J. Rem, J. Klootwijk, C. Cobianu, J. Holleman, J. Verweij. On the Deposition Kinetics of the LPCVD Gate Oxides Prepared from SiH4 and O2. Journal de Physique IV Proceedings, 1995, 05 (C5), pp.C5113-C5-118. 10.1051/jphyscol:1995511 . jpa-00253778

\section{HAL Id: jpa-00253778 https://hal.science/jpa-00253778}

Submitted on 1 Jan 1995

HAL is a multi-disciplinary open access archive for the deposit and dissemination of scientific research documents, whether they are published or not. The documents may come from teaching and research institutions in France or abroad, or from public or private research centers.
L'archive ouverte pluridisciplinaire HAL, est destinée au dépôt et à la diffusion de documents scientifiques de niveau recherche, publiés ou non, émanant des établissements d'enseignement et de recherche français ou étrangers, des laboratoires publics ou privés. 


\title{
On the Deposition Kinetics of the LPCVD Gate Oxides Prepared from $\mathrm{SiH}_{4}$ and $\mathrm{O}_{2}$
}

\author{
J.B. Rem, J.H. Klootwijk, C. Cobianu*, J. Holleman and J.F. Verweij \\ MESA Research Institute, University of Twente, P.O. Box 217, 7500 AE Enschede, The Netherlands \\ * Institute of Microtechnology, P.O. Box 38-160, 72225 Bucharest, Romania
}

\begin{abstract}
An experimental study on the deposition kinetics of $\mathrm{LPCVD} \mathrm{SiO}_{2}$ films at $450^{\circ} \mathrm{C}$ in a hot wall system from $\mathrm{SiH}_{4}$ and $\mathrm{O}_{2}$ in the range of very high $\mathrm{O}_{2} / \mathrm{SiH}_{4}$ ratios (100-284) and very low $\mathrm{SiH}_{4}$ partial pressures (3.5-5.2 $\mu$ bar) is presented. Unexpectediy, a low deposition rate of $1.8 \mathrm{~nm} / \mathrm{min}$ with a thickness uniformity of less than 6 MAXMIN\% on five simultaneously processed wafers is obtained. The results can be explained by a gas phase formation of precursors which dominate the deposition process. This process can be used for different device applications where thin $\mathrm{SiO}_{2}$ films are required, such as Thin Film Transistors and EEPROMs.
\end{abstract}

\section{INTRODUCTION}

The continuous downscaling of electronic devices requires subsequent decreasing film dimensions. Unfortunately, thermal oxides with a thickness below $50 \mathrm{~nm}$ suffer from incorporation of contaminants from the oxidation of silicon, leading to inferior oxide quality. Using deposited oxides one can eliminate the incorporation because no substrate material is consumed for the oxide formation. However, usual deposition rates involved are too high to obtain reproducibly thin layers. Hence, the deposition rates have to decrease.

To improve the quality of thin silane $\left(\mathrm{SiH}_{4}\right)$ based Low Pressure Chemical Vapor Deposition (LPCVD) oxides the oxide defect density is reduced by decreasing the $\mathrm{SiH}_{4}$ partial pressure. Kawahara [1] found that a high $\mathrm{O}_{2} / \mathrm{SiH}_{4}$ ratio (1-10) can result in a uniformly deposited oxide film when a cage with a tightly designed mesh was used in a cold wall reactor. In another paper we have studied the Rapid Thermal Chemical Vapor Deposition (RTCVD) of $\mathrm{SiO}_{2}$ films from $\mathrm{SiH}_{4}$ and $\mathrm{O}_{2}$ with high $\mathrm{O}_{2} / \mathrm{SiH}_{4}$ ratios [2] This also motivated us to investigate the $\mathrm{LPCVD} \mathrm{SiO}_{2}$ formation at high $\mathrm{O}_{2} / \mathrm{SiH}_{4}$ ratios. No detailed kinetic data is known about the combination of a low $\mathrm{SiH}_{4}$ partial pressure (3.5-5.2 $\mu$ bar) and very high $\mathrm{O}_{2}$ / $\mathrm{SiH}_{4}$ ratios (100-300).

It is the purpose of this paper to study the $\mathrm{LPCVD} \mathrm{SiO}_{2}$ deposition rate and thickness uniformity as a function of the $\mathrm{O}_{2} / \mathrm{SiH}_{4}$ ratio, the $\mathrm{SiH}_{4}$ partial pressure and the total pressure. Based on the dependence of the deposition rate on the inter-wafer distance, a gas phase reaction mechanism generating intermediates, which are responsible for the $\mathrm{SiO}_{2}$ formation, is supported. The growth rate and edge nonuniformity can be explained by assuming the gas phase precursor formation to be rate determining.

For Thin Film Transistors to be integrated with sensors and/or displays, it is important to have a low maximum process temperature. The sensors and displays are usually fabricated on glass substrates and, in general, both cannot withstand high temperature steps. For Electrically Erasable Programmable Read Only Memories (EEPROMs) the isolating and tunneling properties must be optimized. Here, the low

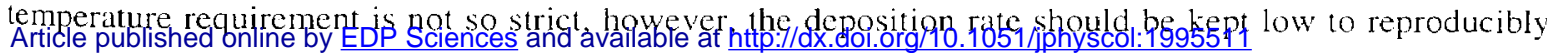


deposit thin oxide layers. The implementation of these oxide films in devices such as TFTs and EEPROMs is subject of research in the near future.

\section{EXPERIMENTAL}

The $\mathrm{SiO}_{2}$ films were deposited at $450^{\circ} \mathrm{C}$ in a hot wall LPCVD reactor using 5.0 quality $100 \% \mathrm{SiH}_{4}$ and $\mathrm{O}_{2}$. See Figure 1 for a schematic presentation. The furnace (1) consists of three separately controlled zones to obtain a flat temperature profile of $30 \mathrm{~cm}$ in the center of the reactor. The reactor is equipped with a $11.5 \mathrm{~cm}$ furnace tube, a wafer "cage" (4) and a cantilever loading system (3), all of them made of quartz. The peculiar aspect of our experimental set-up was that only one orifice injector (2) for silane and oxygen was used, while a simple wafer boat replaced the standard tightly designed cage with orifices. Thirteen 3" wafers were constantly loaded in the carrier (4 dummies in the front and the back and 5 "process" wafers in the middle) for thickness and uniformity control. For a constant flow rate of $\mathrm{SiH}_{4}$ of $4.4 \mathrm{sccm}$, the $\mathrm{O}_{2}$ flow was increased in the range $440-1250 \mathrm{sccm}$ while the total pressure ranged from 0.50 to 1.00 mbar.

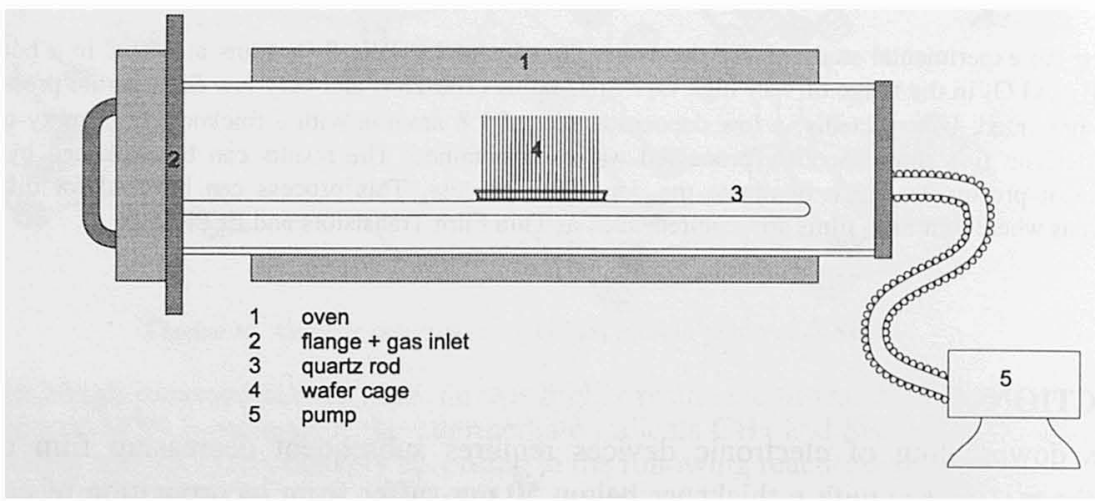

Figure 1:A schematic view of the LPCVD reactor. Dimensions of the tube are: flat zone $=30 \mathrm{~cm}$, diameter $=11.5 \mathrm{~cm}$

The wafers are cleaned as follows: $10 \mathrm{~min}$ in fuming $\mathrm{HNO}_{3}, 5 \mathrm{~min}$ DI water rinse, 10 min in boiling $70 \%$ $\mathrm{HNO}_{3}$ and DI water rinse. Prior to the actual deposition a $1 \% \mathrm{HF}$ dip is given to remove the native oxide. The deposition rate is calculated from the mass increase assuming a double-sided deposition. The thickness is also measured with a PLASMOS ellipsometer using a Helium-Neon laser with a wave length $\lambda$ of $632.8 \mathrm{~nm}$. To eliminate edge effects the thickness uniformity is measured by mapping the thickness across the wafer, taking into account a $10 \mathrm{~mm}$ edge. The thickness uniformity is based on statistical analysis performed by the PLASMOS ellipsometer and is defined in terms of MAXMIN\% around the MEAN value. Therefore, the thickness uniformity is a deviation from the mean value and should be as low as possible. All deposition rate and thickness uniformity values are averaged over five wafers.

\section{RESULTS AND DISCUSSION}

From earlier experience it is clear that the $\mathrm{O}_{2} / \mathrm{SiH}_{4}$ ratio has an important effect on the uniformity and the deposition rate in other CVD reactors $[1,3,4]$. So, it is expected that this ratio is also important for the deposition in the LPCVD reactor used in this study. The results will be presented as a function of $\mathrm{O}_{2} /$ $\mathrm{SiH}_{4}$ ratio and $\mathrm{SiH}_{4}$ partial pressure. The primary goal of our research is to find deposition parameters at a low temperature with a good uniformity and a low deposition rate.

Preliminary experiments are performed to see if the simple experimental setup described above fulfils the requirements for very thin $\mathrm{SiO}_{2}$ deposition. The initial CVD settings are as follows: a deposition 
temperature of $450^{\circ} \mathrm{C}$, a $\mathrm{SiH}_{4}$ flow rate in the range of $10-13 \mathrm{sccm}$, an $\mathrm{O}_{2}$ flow rate in the range of 1200 $1500 \mathrm{sccm}$ and a total pressure in the range of 1.0-1.2 mbar. The inter-wafer spacing is varied between 3$13 \mathrm{~mm}$ to evaluate the effect of the wafer distance on the deposition rate and the thickness uniformity.

This resulted in a deposition rate of 4-6 nm/min while it was 4-5 times lower when the inter-wafer spacing was reduced from 13 to $3 \mathrm{~mm}$. The thickness uniformity is 8-10 MAXMIN\%. This result proves a proportional dependence of the deposition rate on the inter-wafer spacing. From this it is concluded that the gas phase precursor formation dominates the deposition process. The growth rate is then determined by the area to volume ratio.

The deposition rate found with the setting described above (4-6 nm/min) is still quite high for reproducible deposition of thin $\mathrm{SiO}_{2}$ films. Therefore, the deposition rate is further reduced by decreasing the $\mathrm{SiH}_{4}$ partial pressure. In Table 1 the deposition parameters are given.

Table 1: Deposition parameters for the LPCVD oxide from $\mathrm{SiH}_{4}$ and $\mathrm{O}_{2}$.

\begin{tabular}{|l|l|l|l|l|l|l|l|l|}
\hline $\begin{array}{l}\mathrm{O}_{2} \text { flow } \\
\text { [sccm] }\end{array}$ & $\begin{array}{l}\mathrm{N}_{2} \text { flow } \\
{[\mathrm{sccm}]}\end{array}$ & $\begin{array}{l}\mathrm{SiH}_{4} \text { flow } \\
{[\mathrm{sccm}]}\end{array}$ & $\begin{array}{l}\mathrm{O}_{2} / \mathrm{SiH}_{4} \\
\text { ratio }[-]\end{array}$ & $\begin{array}{l}\mathrm{P}(\text { total }) \\
{[\mathrm{mbar}]}\end{array}$ & $\begin{array}{l}\mathrm{P}\left(\mathrm{SiH}_{4}\right) \\
{[\mathrm{mbar}]}\end{array}$ & $\begin{array}{l}\mathrm{P}\left(\mathrm{O}_{2}\right) \\
{[\mathrm{mbar}]}\end{array}$ & $\begin{array}{l}\text { Dep.rate } \\
{[\mathrm{nm} / \mathrm{min}]}\end{array}$ & $\begin{array}{l}\text { Uniformity } \\
{[\%]}\end{array}$ \\
\hline \hline 440 & 0 & 4.4 & 100 & 0.53 & $5.2 \mathrm{e}-3$ & 0.524 & 2.0 & 9.4 \\
\hline 585 & 0 & 4.4 & 133 & 0.63 & $4.7 \mathrm{e}-3$ & 0.625 & 2.48 & 7.3 \\
\hline 750 & 0 & 4.4 & 177 & 0.75 & $4.4 \mathrm{e}-3$ & 0.745 & 2.22 & 7.0 \\
\hline 1000 & 0 & 4.4 & 227 & 0.90 & $3.9 \mathrm{e}-3$ & 0.896 & 1.87 & 4.1 \\
\hline 1250 & 0 & 4.4 & 284 & 1.02 & $3.5 \mathrm{e}-3$ & 1.016 & 1.79 & 5.4 \\
\hline 585 & 750 & 4.4 & 133 & 1.00 & $3.3 \mathrm{e}-3$ & 0.436 & 1.73 & 8.5 \\
\hline
\end{tabular}

As can be seen the $\mathrm{SiH}_{4}$ flow rate is kept constant at the minimum level possible with the equipment used in this study. The $\mathrm{O}_{2} / \mathrm{SiH}_{4}$ ratio is changed by varying the $\mathrm{O}_{2}$ flow rate keeping other parameters as constant as possible. However, due to vacuum pump limitations the pressure can not be kept constant at those high $\mathrm{O}_{2}$ flow rates, thereby changing the partial pressures of $\mathrm{O}_{2}$ and $\mathrm{SiH}_{4}$ simultaneously. Because the $\mathrm{SiH}_{4}$ and $\mathrm{O}_{2}$ partial pressures cannot be separated, the results of the deposition rate and the thickness uniformity will be presented as a function of $\mathrm{O}_{2} / \mathrm{SiH}_{4}$ molar ratio.

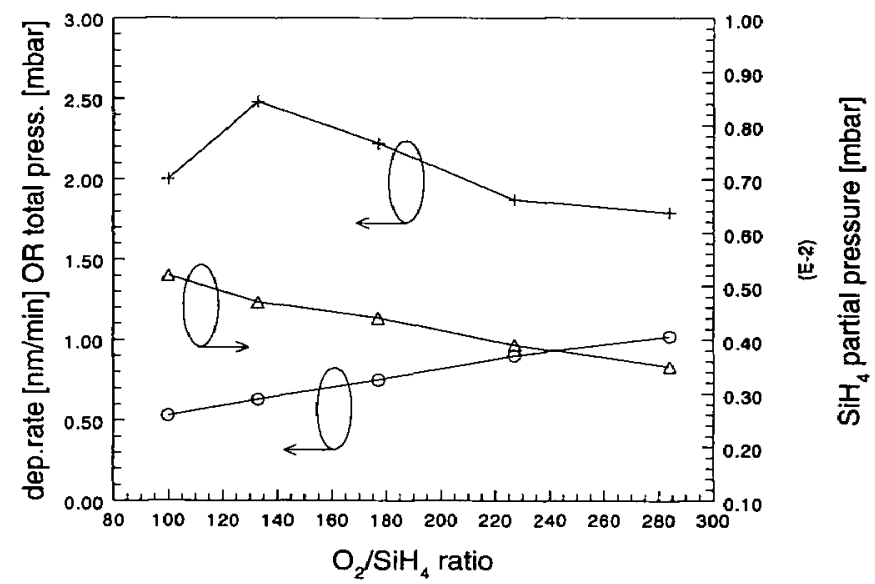

Figure 2:LPCVD $\mathrm{SiO}_{2}$ deposition rate, total and $\mathrm{SiH}_{4}$ partial pressure versus $\mathrm{O}_{2} / \mathrm{SiH}_{4}$ molar ratio at a constant $\mathrm{SiH}_{4}$ flow rate of 4.4 $\mathrm{sccm}$ and a deposition temperature of $450^{\circ} \mathrm{C}(-+-=$ deposition rate in $\mathrm{nm} / \mathrm{min}$ at left $\mathrm{Y}$-axis, $-\Delta-=\mathrm{SiH}_{\downarrow}$ partial pressure in mbar at right $\mathrm{Y}$-axis, $-\mathrm{O}-=$ total pressure in mbar at left $\mathrm{Y}$-axis). 
Figure 2 shows the effect of the $\mathrm{O}_{2}$ flow rate on the $\mathrm{SiO}_{2}$ deposition rate at a constant flow of $\mathrm{SiH}_{4}$. As can be seen a slight increase-maximum-decrease behavior is found for the deposition rate as a function of the $\mathrm{O}_{2} / \mathrm{SiH}_{4}$ molar ratio, although the variation of the deposition rate is very small (from $2.0 \mathrm{~nm} / \mathrm{min}$ to $2.5 \mathrm{~nm} / \mathrm{min}$ and back to $1.8 \mathrm{~nm} / \mathrm{min}$ ), even when the $\mathrm{O}_{2} / \mathrm{SiH}_{4}$ molar ratio is increased to as high as 284. The increase-maximum-decrease behavior is also found in earlier work $[3,4]$ at lower $\mathrm{O}_{2} / \mathrm{SiH}_{4}$ ratios. It should be noted, though, that the residence time and the $\mathrm{SiH}_{4}$ inlet partial pressure are also changed when changing the $\mathrm{O}_{2} / \mathrm{SiH}_{4}$ molar ratio. At high $\mathrm{O}_{2} / \mathrm{SiH}_{4}$ ratios the residence time is short and the effective $\mathrm{SiH}_{4}$ partial pressure at the wafer position is even further decreased. This results in an extension of the $\mathrm{X}$-axis to even higher values so the increase-maximum-decrease behavior as described above is stretched and therefore diminishes. So, the deposition rate is considered to be not depending on very high values of the $\mathrm{O}_{2} / \mathrm{SiH}_{4}$ ratio. The deposition rate is at a level that the control of very thin layers for gate oxide applications is easily obtained.

To eliminate the effect of coupled partial pressures an experiment with $\mathrm{N}_{2}$ addition is performed. By interchanging $\mathrm{N}_{2}$ by $\mathrm{O}_{2}$ the total flow can be kept constant. This can result in a constant residence time and $\mathrm{SiH}_{4}$ partial pressure while the $\mathrm{O}_{2}$ partial pressure can be changed. However, this particular experiment has been conducted at such a high total gasflow that only the $\mathrm{O}_{2} / \mathrm{SiH}_{4}$ ratio could be kept constant. Still, as can be seen from Table 1, the deposition rate decreases with decreasing $\mathrm{SiH}_{4}$ partial pressure while the $\mathrm{O}_{2} / \mathrm{SiH}_{4}$ ratio remains constant (rows 2 and 6), indicating that the $\mathrm{SiH}_{4}$ partial pressure is mainly determining the deposition rate. Comparing the experiments described in rows 5 and 6 , it is seen that, while the $\mathrm{SiH}_{4}$ partial pressure is fairly constant and the $\mathrm{O}_{2}$ partial pressure decreases substantially, the deposition rate is also fairly constant, again indicating that the $\mathrm{SiH}_{4}$ partial pressure is dominating the deposition rate.

As for the thickness uniformity, one observes a decreasing thickness uniformity, which is good by our definition, for the higher $\mathrm{O}_{2} / \mathrm{SiH}_{4}$ molar ratio for the experiments with no $\mathrm{N}_{2}$ addition. This shows that, even for very high $\mathrm{O}_{2} / \mathrm{SiH}_{4}$ molar ratios of 100-284, this ratio affects the thickness uniformity, as was found in earlier works [2-4] for lower ratios.

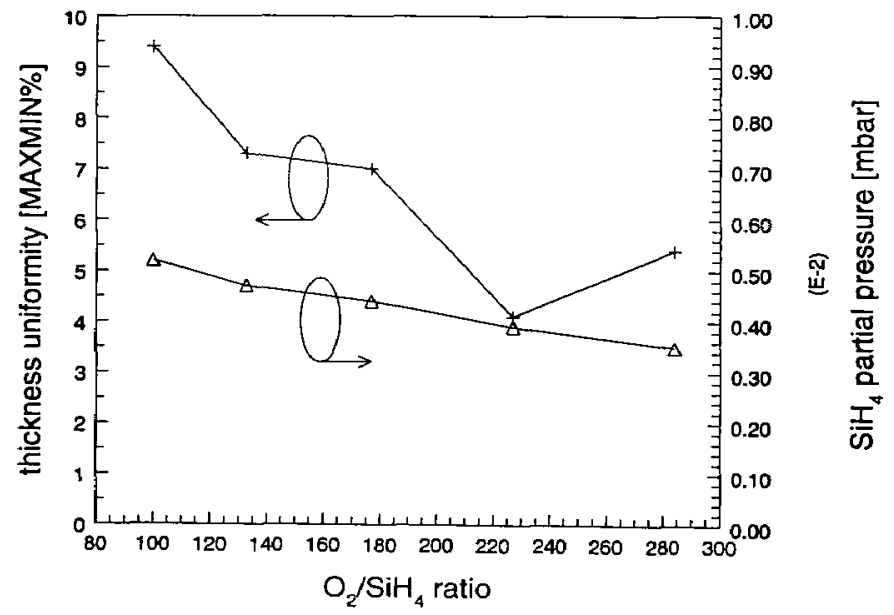

Figure 3: Thickness uniformity and $\mathrm{SiH}_{4}$ partial pressure versus the $\mathrm{O}_{2} /$ $\mathrm{SiH}_{4}$ molar ratio at a constant $\mathrm{SiH}_{4}$ flow rate of $4.4 \mathrm{sccm}$ and a deposition temperature of $450^{\circ} \mathrm{C}(-+=$ thickness uniformity in $\%$, $-\Delta^{-}=\mathrm{SiH}_{4}$ partial pressure in mbar). 
For thin oxide layers a low deposition rate is necessary for controllable growth. A high $\mathrm{O}_{2} / \mathrm{SiH}_{4} \mathrm{molar}$ ratio seems interesting since the deposition rate is reasonably constant at a low value. So, for a high $\mathrm{O}_{2} /$ $\mathrm{SiH}_{4}$ molar ratio of 227 the thickness uniformity is the most important parameter.

From Figure 3, a trend of improving LPCVD $\mathrm{SiO}_{2}$ thickness uniformity is observed when the $\mathrm{O}_{2} / \mathrm{SiH}_{4}$ molar ratio is increased. The edges are always thicker compared to the center of the wafer, giving information about the deposition mechanism at $450^{\circ} \mathrm{C}$. An increasing $\mathrm{O}_{2} / \mathrm{SiH}_{4}$ ratio also increases the total pressure. This usually results in a deterioration of the thickness uniformity. However, for this particular situation of very low $\mathrm{SiH}_{4}$ partial pressure and high $\mathrm{O}_{2} / \mathrm{SiH}_{4}$ molar ratio the uniformity is slightly improving, suggesting that the effect of increasing $\mathrm{O}_{2} / \mathrm{SiH}_{4}$ molar ratios on improvement of the thickness uniformity is higher than the deleterious one due to the total pressure increase.

The inter-wafer spacing has a large effect on the deposition rate and the thickness uniformity, in agreement with earlier reports [5,6]. In our case, when the wafer spacing is reduced from $13 \mathrm{~mm}$ to $3 \mathrm{~mm}$, the deposition rate decreases by about 5 times. Therefore, a decrease of the deposition rate by the ratio of the distances between the wafers exists. Because of the smaller inter-wafer spacing, any small tilt of a wafer affects the thickness uniformity. From this it can be concluded that the gas phase precursor formation dominates the deposition process. The growth rate is then determined by the area to volume ratio.

\section{DISCUSSION}

The driving force for the investigation of $\mathrm{LPCVD} \mathrm{SiO}_{2}$ film deposition kinetics under the CVD conditions described above (low $\mathrm{SiH}_{4}$ partial pressure and high $\mathrm{O}_{2} / \mathrm{SiH}_{4}$ molar ratio) is mainly the low deposition temperature required for glass compatibility and the low deposition rate necessary for very thin (gate) oxide applications.

At deposition temperatures higher than $400^{\circ} \mathrm{C}$ the deposition mechanism appears to be mass transport controlled. The deposition mechanism is still under consideration in the literature $[3,6]$. The dependence of the deposition rate on the wafer to wafer distance in an LPCVD reactor is explained based on the surface reaction mechanism [5]. Later, for LPCVD conditions, a mechanism based on gas phase reactions which provided one [6] or two [1] precursors was suggested. According to the mechanism based on the gas phase precursors and the volume needed to create these, one can easily explain the higher thickness of the oxide layer at the edge of the wafer. Also, the reduction of the deposition rate found when the interwafer spacing is decreased can be explained in this way.

A major problem with the theoretical description of the deposition in the system used in this study is the fact that the $\mathrm{SiH}_{4}$ and $\mathrm{O}_{2}$ partial pressures are coupled. For the calculation of deposition rate as a function of both $\mathrm{SiH}_{4}$ partial pressure and total pressure the pressures should be separated. This is not possible due to the vacuum pump limitations.

The main reasons for selecting the deposition temperature of $450^{\circ} \mathrm{C}$ are related to the removal of all Si-H unreacted bonds from the film deposition [7] and a good step-coverage [1]. These are very important from the device point of view. The first property, the elimination of Si-H bonds from the bulk of the dielectric, is necessary to reduce the number of charge carrier traps. The second property, the oxide conformity, is needed for second level poly-silicon overlapping the first level of poly-silicon.

An overall analysis of the experimental results in our laboratory shows only a slight dependence of the deposition rate and thickness uniformity on the deposition parameters. This is very different from earlier results obtained in a standard LTO reactor $[3,4]$, probably due to the much higher $\mathrm{O}_{2} / \mathrm{SiH}_{4}$ molar ratios. Moreover, in that paper [3], it is shown that for a higher $\mathrm{SiH}_{4}$ partial pressure $(\approx 3 \mathrm{mbar})$ at $400^{\circ} \mathrm{C}$, a strong gas phase reaction started when the $\mathrm{O}_{2} / \mathrm{SiH}_{4}$ ratio exceeded a certain value. This value is a function of temperature, increasing when the deposition temperature increases. Although in our simple setup the $\mathrm{SiH}_{4}$ 
partial pressure is two or three orders of magnitude lower, it can not be excluded that gas phase reactions start to play a role at the higher $\mathrm{SiH}_{4}$ partial pressures at $450^{\circ} \mathrm{C}$.

Some preliminary electrical characterisation is performed on simple capacitor structures after the $50 \mathrm{~nm}$ oxide films are annealed in $\mathrm{N}_{2}$ at $950^{\circ} \mathrm{C}$ for 15 minutes for densification. The results are promising as a charge-to-breakdown value of $0.5 \mathrm{C} / \mathrm{cm}^{2}$ is found for several capacitors. Further electrical characterisation is necessary to assess the properties of these thin oxide layers in devices like thin film transistors and EEPROMs.

The optimum CVD deposition conditions which assure a low deposition rate of $1.8 \mathrm{~nm} / \mathrm{min}$ and a thickness uniformity (taking into account a $10 \mathrm{~mm}$ wafer edge) of less than 6 MAXMIN\% on five wafers simultaneously are:

1. $\mathrm{A} \mathrm{SiH}_{4}$ flow rate of $4.4 \mathrm{sccm}$

2. $\mathrm{A} \mathrm{O}_{2}$ flow rate of $1250 \mathrm{sccm}\left(\mathrm{O}_{2} / \mathrm{SiH}_{4}\right.$ ratio of 227)

3. A total pressure of $1.0 \mathrm{mbar}$

4. A deposition temperature of $450^{\circ} \mathrm{C}$

\section{CONCLUSIONS}

In this work the deposition of thin $\mathrm{SiO}_{2}$ layers from $\mathrm{SiH}_{4}$ and $\mathrm{O}_{2}$ in a standard LPCVD reactor without using complex $\mathrm{O}_{2}$ and $\mathrm{SiH}_{4}$ distribution systems is shown. A low deposition rate of $1.8 \mathrm{~nm} / \mathrm{min}$ with a thickness uniformity of less than 6 MAXMIN\% on five simultaneously processed wafers is obtained for a $\mathrm{SiH}_{4}$ partial pressure of $3.5^{*} 10^{-3}$ mbar and a $\mathrm{O}_{2} / \mathrm{SiH}_{4}$ ratio of 227 . The results can be explained by assuming the gas phase precursor formation to be dominating the deposition process.

This process can be used for different device applications where thin $\mathrm{SiO}_{2}$ films are required, the first priority being in the field of Thin Film Transistors and EEPROMs. To meet these requirements, the defect density, step coverage and resistance against hot electron stress and Fowler-Nordheim tunneling must be studied initially. The effect of densification steps will be subject of research in the very near future.

\section{Acknowledgements}

The technical support provided by the staff of the Clean Room of the MESA Research Institute at the University of Twente is gratefully acknowledged. This work is financed by the Dutch Foundation for Fundamental Research on Matter (FOM) under the project number TEL 88074.

\section{References}

1 Kawahara, T. et. al., Jap. J. Appl. Phys., 30, (1991) 431-436

2 Cobianu, C., Rem, J.B. et.al., to be published

3 Cobianu, C. and Pavelescu, C., J. Electrochem. Soc. 130, (1983) 1888-1893

4 Cobianu, C., Thin Solid Films, 226, (1993) 1-2

5 Learn, A. J., J. Electrochem. Soc., 132, (1985) 390-393

6 Watanabe, K. and Komiyama, H., J. Electrochem. Soc., 137, (1993) 1222-1227

7 Pavelescu, C. et.al., J. Electrochem. Soc, 130, (1983) 975-977 